\title{
Trace elements and septic shock in elderly patients
}

\author{
Hamza SA ${ }^{1}$, Ali SH*1, Abdul Kadir KA ${ }^{2}$ and Shaat MM $^{1}$ \\ 1 Geriatrics \& Gerontology department, Faculty of Medicine, Ain Shams University, Cairo, Egypt. \\ 2 Cardiology Department; Faculty of Medicine, Ain shams university, Cairo, Egypt
}

\begin{abstract}
Background: Trace elements like copper and zinc have a significant influence on the function of the immune system.
\end{abstract}

Aim: To evaluate baseline trace elements as s predictor of septic shock in Egyptian elderly patients within intensive care setting.

Methods: A prospective study for all patients admitted to Ain Shams Geriatrics intensive care unit (ICU) during a 6 months period. Patients divided to: group who did not develop septic shock and those who developed septic shock. APACHE II score (Acute Physiology and Chronic Health Evaluation II), systemic inflammatory response (SIR) and vital signs were verified. Routine laboratory tests, conscious level and length of stay were recorded. Trace elements (zinc $(\mathrm{Zn})$ and copper $(\mathrm{Cu}))$ were analysed.

Results: The sample included 142 patients (49\% females). The mean age was $69.5 \pm 7.3$. Septic shock was observed in $12 \%$ of them. There was a statistically significant difference between septic and non-septic shock patients as regards baseline serum zinc level $(P \leq 0.001)$ but no difference regarding serum copper level ( $p \geq 0.05)$.

Conclusions: The study highlighted that baseline zinc deficiency may add to the risk of developing septic shock in elderly patients. However, further studies are needed to confirm such association

Keywords: septic shock- elderly-zinc- copper.

\section{Background:}

Sepsis is defined as an inflammatory body response to infection, with severe sepsis and septic shock being its more severe forms. ${ }^{1}$ Despite advances in the management of septic patients, sepsis is still the second leading cause of death among patients in non-coronary intensive care units (ICU). ${ }^{2}$ The number of elderly admitted to ICU is increasing in recent years due to increase survival. $^{3}$

Routinely, the macronutrient contribution is thoroughly studied when a patient is admitted to ICU. However, it must be kept in mind that along with macronutrients, micronutrients are also significant, and these must be taken into account. Previous studies tackled trace elements in relation to surgery complications ${ }^{4}$, and total parenteral nutrition. ${ }^{5}$ Concerning sepsis, some studies were conducted to evaluate if trace elements are related to inflammation ${ }^{6}$, critical illness ${ }^{7}$ and if supplementation would affect the outcome. ${ }^{8}$

We aimed to evaluate baseline trace elements as $\mathrm{s}$ predictor of septic shock in Egyptian elderly patients within intensive care setting.

\section{Methods}

Prospective observational single central cohort study included all patients $\geq 60$ years old, admitted to geriatric ICU during a 6 months period. Patients admitted for brief postoperative monitoring were excluded. The subjects were further subdivided into two groups.

First group includes patients who developed septic shock. The second group included patients who did not develop septic shock. 
.Each patient was evaluated using APACHEII 9, Systemic inflammatory response syndrome (SIRS) ${ }^{10}$, delirium assessment using The Confusion Assessment Method (CAM)). ${ }^{11}$ Laboratory investigations (complete blood picture, Creatinine, urea, albumin, total protein, sodium and potassium.

Trace elements (serum $\mathrm{Cu}$ and $\mathrm{Zn}$ levels were measured. The reference range for $\mathrm{Cu}$ was 70-145 $\mu \mathrm{g}$ $\mathrm{dL}-1$ and for $\mathrm{Zn} 70-120 \mu \mathrm{g} \mathrm{dL}-1$.

Diagnosis of septic shock was defined according to the International Sepsis Definitions Conference. ${ }^{12}$

\section{Ethical consideration}

Informed oral consent was taken from the patient or care giver after explanation of the study aim and procedure and the study methodology was reviewed and approved by the Research Review Board of the Geriatrics and Gerontology Department, Faculty of medicine, Ain Shams University.

\section{Statistical Analysis}

The collected data were coded, tabulated, and statistically analyzed using SPSS version 22.0 (SPSS, Chicago, IL,USA). Quantitative variables were presented in the form of means and standard deviations. Qualitative variables were presented in the form of frequency tables (number and percent).

\section{Results}

There was no statistically significant difference between both groups as regards age, sex, BMI and length of stay. [Table (1)]

There was a statistically significant difference between both groups as regards APACHE score and SIR but no difference as regard development of delirium [Table (2)]. Regarding laboratory investigations, only serum zinc was significantly different between both groups. [Table (3)]

Table (1): Demography of the study population

\begin{tabular}{|c|c|c|c|c|}
\hline \multicolumn{2}{|c|}{ Age (years) } & $\begin{array}{l}\text { No- septic } \\
\text { shock } \\
(\mathbf{1 2 7}) \\
69.2 \pm 7.2\end{array}$ & $\begin{array}{l}\text { Septic } \\
\text { shock } \\
(15) \\
73.0 \pm 8.0\end{array}$ & $\begin{array}{l}\text { P- } \\
\text { valu } \\
\text { e } \\
0.09\end{array}$ \\
\hline \multirow[t]{2}{*}{ Sex } & Male & $64(51 \%)$ & $8(50 \%)$ & \multirow[t]{2}{*}{1} \\
\hline & Female & $63(49 \%)$ & $7(50 \%)$ & \\
\hline \multicolumn{2}{|c|}{ BMI } & $24.5 \pm 7.3$ & $26.7 \pm 8.6$ & 0.36 \\
\hline \multicolumn{2}{|c|}{$\begin{array}{l}\text { Length of stay } \\
\text { (days) }\end{array}$} & $4.35 \pm 1.8$ & $4.1 \pm 2.0$ & 0.62 \\
\hline
\end{tabular}

Body mass index : BMI
Table 2: Clinical scales according to the presence of septic shock

\begin{tabular}{|c|c|c|c|c|}
\hline & & $\begin{array}{l}\text { No- } \\
\text { septic } \\
\text { shock } \\
(127)\end{array}$ & $\begin{array}{l}\text { Septic } \\
\text { shock } \\
(15)\end{array}$ & P-value \\
\hline APACHE II & & $13 \pm 5$ & $25 \pm 9$ & $<0.001$ \\
\hline \multirow[t]{2}{*}{ CAM } & Positive & 41 & 11 & \multirow[t]{2}{*}{0.77} \\
\hline & Negative & 86 & 4 & \\
\hline \multirow[t]{2}{*}{ SIRS } & Positive & 31 & 14 & \multirow[t]{2}{*}{$<0.001$} \\
\hline & Negative & 96 & 1 & \\
\hline
\end{tabular}

SIRS: Systemic inflammatory response syndrome

Table 3: laboratory investigations in both groups

\begin{tabular}{llll}
\hline & $\begin{array}{l}\text { No- } \\
\text { septic } \\
\text { shock } \\
(127)\end{array}$ & $\begin{array}{l}\text { Septic } \\
\text { shock } \\
(15)\end{array}$ & P-value \\
\hline Zinc Ug/dl & $127 \pm 81$ & $82 \pm 40$ & $<0.001$ \\
Copper $\boldsymbol{\mu g / d L}$ & $121 \pm 65$ & $122 \pm 48$ & 0.93 \\
Sodium mEq/L & $135.4 \pm 8$ & $134.7 \pm 9$ & 0.76 \\
\hline Potassium mEq/L & $4.0 \pm 0.8$ & $4.4 \pm 0.8$ & 0.12 \\
Magnesium mg/dL & $1.9 \pm 0.4$ & $1.8 \pm 0.3$ & 0.11 \\
Phosphorous mg/dL. & $3.3 \pm 1.6$ & $4.2 \pm 2.4$ & 0.16 \\
\hline Calcium mg/dL & $8.7 \pm 1.1$ & $8.4 \pm 0.8$ & 0.22 \\
Chloride mEq/L & $108 \pm 11$ & $109 \pm 9$ & 0.87 \\
\hline
\end{tabular}

Table 4: Correlation between Copper, Zinc and Magnesium \& APACHE score among the study groups

\begin{tabular}{lll}
\hline & APACHE II & P-value \\
\hline Zinc Ug/dl & -0.061 & 0.47 \\
Copper $\boldsymbol{\mu g} / \mathbf{d L}$ & 0.024 & 0.79 \\
Magnesium mg/dL & 0.01 & 0.88 \\
\hline
\end{tabular}

\section{Discussion}

This study analyzed if baseline trace elements can forecast septic shock in elderly patients in whom we used to see atypical picture overwhelming and a challenging diagnosis which may be missed if not expected.

The study highlighted that trace elements on admission could help to stratify the patients risk to develop septic shock in elderly. In the current study, there was a statistically significant difference between septic and non-septic shock groups as regards serum zinc but no difference regarding serum copper. The study added to the substantial literature that has called into question the consistency of trace elements measurements in clinical practice particularly for elderly people. 
It was shown that oxidative stress changes trace elements levels. ${ }^{13}$ Trace element levels in critical patients were decreased by factors such as increased oxidative stress, use of anti-oxidant systems, haemodilution with fluid resuscitation, renal replacement therapies, losses in biological fluids and inadequate intake. ${ }^{14}$ Systemic inflammation affected oxidative stress in sepsis and SIRS. Iron, selenium, copper and zinc are required for the activity of antioxidant enzymes. Low-trace elements are associated with higher risk of death, SIRS, multiple organ failure (MOF) and higher oxidative stress in critically ill patients. ${ }^{14}$

Srinivas et al, 1988 studied plasma levels of trace elements in 53 patients with acute bacterial and viral infections. They found that Plasma copper was unchanged in patients with erysipelas, but increased in other types of bacterial infections. Furthermore, in viral infections $60 \%$ of the zinc values were below the mean level observed in healthy controls as compared with $90 \%$ of the values in patients with sepsis or $92 \%$ of the values in patients with pneumonia. The onset of change in trace elements occurred within a few days and persisted for several weeks. ${ }^{15}$

Another study by Saner et al, 2000, although on infants, investigated 22 infants with sepsis syndrome, Serum zinc and copper levels were lower in infants with sepsis compared to healthy infants and infants with mild infection, but the differences were not significant. ${ }^{16}$

A recent study by Ayoglu et al, 2016 evaluate the changing levels of selenium, copper, zinc and iron in patients with sepsis and systemic inflammatory response syndrome and their influence on mortality. Blood samples were taken on $1 \mathrm{st}, 3 \mathrm{rd}$, 5th and 7 th days. Of the 57 patients, Copper and zinc levels were in the normal range, while selenium and iron levels were lower than the limit values at all measuring periods. There was no significant difference between first and other days in accordance with element levels $(\mathrm{p}>0.05)^{17}$

Stefanowicz et al, 2014 evaluated 125 patients who were admitted to intensive care unit with evidence of systemic inflammatory response. Copper, zinc, and selenium concentrations were measured in plasma and erythrocytes and results related to mortality and patient outcome measures. Plasma zinc and selenium concentrations were significantly lower on admission compared with reference intervals, whereas copper was increased. No significant difference of plasma selenium and zinc between survivors and non-survivors was found although they measured erythrocytes level simultaneously. ${ }^{18}$

Jang et al, 2014 determine how serum selenium and zinc affect the outcomes of critically ill surgical patients. Mean selenium concentrations were significantly different in patients with and without shock $(77.9 \pm 25.4$ and $87.2 \pm 23.1 \mathrm{ng} / \mathrm{dL}, \mathrm{P}=.017)$. Furthermore, mean serum selenium was lower in patients with sepsis than in traumatic or simply postoperative patients $(\mathrm{P}<.001$ and $\mathrm{P}=.038)$. Serum $\mathrm{Zn}$ was significantly lower in patients with sepsis than in patients with trauma. ${ }^{19}$

Cander et al, 2011 enrolled 36 patients, with a median age of 70.5 years (range, 18-87 years), Serum zinc levels were found to be inversely correlated with SOFA scores $(r=-0.41, P<.01)$. The result of this study supports the fact that organ failure and critical illness lead to a decline in serum zinc concentrations and that administration of zinc may be beneficial for critically ill patients. In that study, they measured the consequent serum zinc and not the baseline. ${ }^{20}$

$\mathrm{Zn}$ is an essential trace element, co-factor of CopperZinc superoxide dismutase (SOD) enzyme, plays an important role for host response to infection. In SOD enzyme, $\mathrm{Zn}$ causes the enzyme to keep stability and Copper is responsible for the activity of the enzyme ${ }^{21}$. Clinical researches have reported that $\mathrm{Zn}$ deficiency correlates with an increased severity of illness and progress of MOF in patients with sepsis 22 .

$\mathrm{Zn}$ supplementation is still controversial. There is no recommendation for routine $\mathrm{Zn}$ supplementation in critically ill patients. Some of studies have concluded that low plasma $\mathrm{Zn}$ levels are usually misinterpreted for $\mathrm{Zn}$ deficiency and $\mathrm{Zn}$ is unnecessarily supplemented 23. In our study, zinc was found to be significantly associated with incidence of septic shock.

Copper $(\mathrm{Cu})$ is important for collagen synthesis, antioxidant activity, iron transport and can cause anemia, leukopenia and pancytopenia also acts as a cofactor for oxidative metalloenzymes ${ }^{24} \mathrm{Cu}$ deficits can contribute to the development and progression of cardiovascular disease and diabetes ${ }^{25} . \mathrm{Cu}$ has significant effects on lipid peroxidation. Also, it was reported that myocardial infarction risk was four times more in humans with high plasma $\mathrm{Cu}$ levels in comparison with the normal population as a result of negative effects of lipid peroxidation on the vessel walls. ${ }^{26}$

It was found that in hypertensive patients, basal $\mathrm{Cu}$ levels were higher and 7 th day $\mathrm{Cu}$ levels were lower than non-hypertensive patients. Copper in the vessel wall that causes lipid peroxidation may explain higher basal $\mathrm{Cu}$ levels in the hypertensive patients. In patients with cancer, it was stated that serum $\mathrm{Cu} / \mathrm{Zn}$ ratio increased significantly in the advanced stages. $^{27}$ 
In the present study, a basal $\mathrm{Cu}$ level was not found to be significantly associated with incidence of septic shock.

The main strength of the study was that patients were recruited randomly from a mixed group of elderly patients. The data collected prospectively and combined vital signs, outcome score and biomarkers. A major weakness is that we did not include young patients to study if it will differ. Furthermore, a bigger sample size was hindered by the age limit and the exclusion criteria. Further studies are needed to know if zinc supplementation would affect progression to septic shock and could favor the outcome.

\section{Conclusion}

The baseline serum zinc level can be a reliable sign to predict septic shock occurrence. This may emphasize the importance of such simple and cheap assessment in this dangerous subset of patients.

\section{References}

1. Levy, Mitchell M., et al. "2001 sccm/esicm/accp/ats/sis international sepsis definitions conference." Intensive care medicine 2003: 29.4 530-538.

2. Martin GS, Mannino DM, Moss M. The effect of age on the development and outcome of adult sepsis. Crit Care Med. 2006;34:15-21.

3. Bagshaw SM, Webb SA, Delaney A, George C, Pilcher D, Hart GK, et al. Very old patients admitted to intensive care in Australia and New Zealand: a multi-centre cohort analysis. R45Crit Care. 2009;13(2)

4. Liu, Ming-Yi, et al. Influence of preoperative peripheral parenteral nutrition with micronutrients after colorectal cancer patients. BioMed research international 2015.

5. Livingstone, Callum. Zinc: physiology, deficiency, and parenteral nutrition. Nutrition in Clinical Practice 2015: 30.3: 371-382.

6. Galloway, Status Peter, Donald C. McMillan, and Naveed Sattar. "Effect of the inflammatory response on trace element and vitamin status." Annals of clinical biochemistry 2000: 37.3: 289-297.

7. Agarwal, Anil, et al. Trace elements in critical illness. Journal of Endocrinology and Metabolism 2011: 1(2) 57-63.

8. Beale, Richard J., et al. Early enteral supplementation with key pharmaconutrients improves Sequential Organ Failure Assessment score in critically ill patients with sepsis: outcome of a randomized, controlled, double-blind trial.Critical care medicine 2008: 36.1 131-144.

9. Knaus, William A, et al. APACHE II: a severity of disease classification system.Critical care medicine 1985, $13.10: 818-829$.

10. Knaus WA, Sun $X$, Nystrom $O$, Wagner DP. Evaluation of definitions for sepsis. Chest. 1992;101:1656-62. doi: 10.1378/chest.101.6.1656

11. Inouye SK, Van Dyck CH, Alessi CA, et al. Clarifying confusion: the Confusion Assessment Method. A new method for detection of delirium. Ann Intern Med. 1990;113:941-8

12. Levy MM, Fink MP, Marshall JC, et al. 2001 SCCM/ESICM/ACCP/ATS/SIS international sepsis definitions conference. Crit. Care Med. 2003;31(4):1250-1256.

13. Akin M, Ayoglu H, Okyay D, Ayoglu F, Gür A, Can M, et al. Effects of various anesthesia maintenance on serum levels of selenium, copper, zinc, iron and antioxidant capacity. Braz J Anesthesiol. 2015; 65: 51-60.

14. Manzanares W, Langlois PL, Hardy G. Update on antioxidant micronutrients in the critically ill. Curr Opin Clin Nutr Metab Care. 2013; 16: 719-2.

15. Srinivas, U., et al. Trace element alterations in infectious diseases.Scandinavian journal of clinical and laboratory investigation 48.6 (1988): 495-500.Gauer RL. Early recognition and management of sepsis in adults: the first six hours. Am Fam Physician. 2013;88(1):44-53
16. Saner, Günay, et al. Serum zinc, copper levels, and copper/zinc ratios in infants with sepsis syndrome. The Journal of trace elements in experimental medicine .2000,13.(3): 265-270.

17. Ayoglu, Hilal, et al. Selenium, copper, zinc, iron levels and mortality in patients with sepsis and systemic inflammatory response syndrome in Western Black Sea Region, Turkey." JPMA. The Journal of the Pakistan Medical Association. 2016: 66(4): 447452.

18. Stefanowicz, Fiona et al. Assessment of plasma and red cell trace element concentrations, disease severity, and outcome in patients with critical illness. Journal of critical care .2014: 29. (2): 214-218.

19. Jang, Ji Young, et al. Serum selenium and zinc levels in critically ill surgical patients." Journal of critical care 2014: 29. (2): 317-e5.

20. Cander, Basar, et al. Prognostic value of serum zinc levels in critically ill patients. Journal of critical care. 2011, 26. (1): 42-46.

21. Richardson J, Thomas KA, Rubin BH, Richardson DC. Crystal structure of bovine $\mathrm{Cu}, \mathrm{Zn}$ superoxide dismutase at $3 \mathrm{~A}$ resolution: chain tracing and metal ligands. Proc Natl Acad Sci USA.1975; 72: 1349-53.

22. Besecker BY, Exline MC, Hollyfield J, Phillips G, Disilvestro RA Wewers MD, et al. A comparison of zinc metabolism, inflammation, and disease severity in critically ill infected and noninfected adults early after intensive care unit admission. Am J Clin Nutr. 2011; 93:1356-64.

23. Duncan A, Dean P, Simm M, O'Reilly DS, Kinsella J. Zinc supplementation in intensive care: results of a UK survey. J Crit Care. 2012; 27: 102.e1-102.e6.

24. Robinson S, Cooper B, Leday T. Copper deficiency (hypocupremia) and pancytopenia late after gastric bypass surgery. Proc (Bayl Univ Med Cent) 2013; 26: 382-6.

25. Uriu-Adams JY, Keen CL. Copper, oxidative stress, and human health. MOI Aspects Med. 2005; 26: 268-98.

26. Salonen JT, Salonen R, Korpela H, Suntioinen S, Tuomilehto J. Serum copper and the risk of acute myocardial infarction: prospective population study in men in eastern Finland. Am J Epidemiol. 1991; 134: 268-76.

27. Ma EL, Jiang ZM. Ion-exchange chromatography in simultaneous determination of serum, copper and zinc levels in patients with cancer of digestive tract. Chim Med J (Engl). 1993; 106:118-21. 